University of Nebraska - Lincoln

DigitalCommons@University of Nebraska - Lincoln

Faculty Publications from the Harold W. Manter Laboratory of Parasitology

$12-1991$

Phylogenetic Analysis of Alloglossidium Simer, 1929 (Digenea: Plagiorchiiformes: Macroderoididae) with Discussion of the Origin of Truncated Life Cycle Patterns in the Genus

Joseph P. Carney

University of Manitoba

Daniel R. Brooks

University of Toronto, dnlbrooks@gmail.com

Follow this and additional works at: https://digitalcommons.unl.edu/parasitologyfacpubs

Part of the Parasitology Commons

Carney, Joseph P. and Brooks, Daniel R., "Phylogenetic Analysis of Alloglossidium Simer, 1929 (Digenea: Plagiorchiiformes: Macroderoididae) with Discussion of the Origin of Truncated Life Cycle Patterns in the Genus" (1991). Faculty Publications from the Harold W. Manter Laboratory of Parasitology. 243.

https://digitalcommons.unl.edu/parasitologyfacpubs/243

This Article is brought to you for free and open access by the Parasitology, Harold W. Manter Laboratory of at DigitalCommons@University of Nebraska - Lincoln. It has been accepted for inclusion in Faculty Publications from the Harold W. Manter Laboratory of Parasitology by an authorized administrator of DigitalCommons@University of Nebraska - Lincoln. 


\title{
PHYLOGENETIC ANALYSIS OF ALLOGLOSSIDIUM SIMER, 1929 (DIGENEA: PLAGIORCHIIFORMES: MACRODEROIDIDAE) WITH DISCUSSION OF THE ORIGIN OF TRUNCATED LIFE CYCLE PATTERNS IN THE GENUS
}

\author{
Joseph P. Carney* and Daniel R. Brooks \\ Department of Zoology, University of Toronto, Toronto, Ontario, Canada M5S 1A1
}

\begin{abstract}
Alloglossidium comprises 9 species of North American plagiorchiiform digeneans using ictalurid catfish, freshwater crustacea, and hirudinid leeches as definitive hosts. Two hypotheses about the evolution of this array of definitive hosts were examined using phylogenetic systematic analysis. Two most parsimonious trees, based on 15 homologous series derived from morphological data, each indicated the 2 species utilizing ictalurid catfish definitive hosts are basal members of the group, whereas the 2 species using freshwater crayfish definitive hosts and the 5 utilizing leech definitive hosts each comprise relatively derived monophyletic sister groups. The results suggest that species using crustaceans as definitive hosts are derived by life cycle truncation, whereas those using leeches as definitive hosts appear to be derived through a switch from crustaceans to leeches.
\end{abstract}

Most digeneans use vertebrates as definitive hosts. The genus Alloglossidium Simer, 1929, is unusual because, although 2 species use ictalurid catfish as definitive hosts, 2 others use freshwater crustaceans and the remaining 5 use leeches as their respective definitive hosts. Two hypotheses have been proposed to explain the diversity of definitive host types in this group.

Font (1980) proposed that species inhabiting catfish exhibit the primitive life cycle pattern (gastropod first intermediate host, arthropod second intermediate host, vertebrate definitive host) for the group. He postulated that species utilizing crustaceans and those utilizing leeches as definitive hosts represent 2 independent evolutionary lineages. In each lineage, the vertebrate definitive host was lost from the life cycle through precocial maturation of the metacercarial stage in what was primitively the second intermediate host. Riggs and Ulmer (1983) proposed that Alloglossidium species using leeches evolved prior to those using ictalurid catfish (they did not address the species inhabiting freshwater crustaceans). According to this hypothesis, the evolution of complex digenean life cycles was allowed by the evolution of complex aquatic and semiaquatic food chains consisting of various invertebrates. As vertebrates evolved they displaced the higher order invertebrate consumers from their positions in the food chains. Riggs and Ulmer (1983), citing similarity between leech intestines and catfish

Received 26 November 1990; revised 10 July 1991; accepted 31 July 1991.

* Present address: Department of Zoology, University of Manitoba, Winnipeg, Manitoba, Canada R3T 2N2. intestines, hypothesized that Alloglossidium species using leeches were preadapted to inhabiting catfish. Thus, when catfish evolved, they displaced the higher order leech consumers and were colonized by Alloglossidium.

In this study, both a phylogenetic systematic reconstruction of relationships among the species of Alloglossidium and examination of ecological correlates of their phylogenetic diversification were examined to evaluate each of these hypotheses.

\section{MATERIALS AND METHODS \\ Phylogenetic analysis}

Phylogenetic analysis of the species of Alloglossidium was performed using 15 putative homologous series derived from adult morphology. Character data were obtained by examination of type specimens for each species, obtained from the U.S. National Museum Helminthological Collection, Beltsville, Maryland (USNM), voucher specimens in the collection of the Harold W. Manter Laboratory, University of Nebraska State Museum (HWML), and specimens from the personal collections of Dr. W. F. Font (WFF), Dr. M. Riggs (MR), and the first author (JPC). Specimens were examined with a light microscope using brightfield, phase-contrast, and differential interference contrast illuminations. Drawings were made with the aid of a drawing tube. Unless noted otherwise, measurements are in micrometers, with the range followed by the mean in parentheses.

\section{Species incertae sedis}

Alloglossidium glyptosterni Moravec and Amin, 1978, was described from Glyptosternum reticulatum Gibbes, 1850, a species of catfish found in Afghanistan (Moravec and Amin, 1978). The description was based on a single specimen and its placement in Alloglossidium was, by the authors' own account, provisional, and they acknowledged that it may have been a specimen of 
Orientocreadium siluri. From the description and figures given, it is doubtful that the specimen as described belongs in the genus Alloglossidium. The vitellaria in A. glyptosterni are reported to fill the posttesticular space. In the North American species of Alloglossidi$u m$, the vitellaria are lateral bands that do not extend into the posttesticular space. Moravec and Amin (1978) reported a seminal receptacle for $A$. glyptosterni, a character lacking (Vande Vusse, 1980) in the North American species of Alloglossidium. The cirrus of A. glyptosterni is very long whereas the cirrus in the North American species is greatly reduced. A further consideration is geographical separation. All other species in the genus have been reported only from North America, whereas $A$. glyptosterni has been reported only from Afghanistan. Although this in itself would be insufficient to remove $A$. glyptosterni from the genus, coupled with the morphological considerations it amounts to a compelling argument. Therefore based on posterior extent of the vitellaria, presence of a seminal receptacle, possession of a well developed cirrus, and biogeographic separation, A. glyptosterni does not belong in the genus Alloglossidium, and it was not considered in the following analysis.

\section{Character analysis}

Character polarity was determined by outgroup comparisons (Watrous and Wheeler, 1981; Maddison et al., 1984) using species of Macroderoides as the primary outgroup. Macroderoides is considered to be the sister group of Alloglossidium because, among species assigned to the Macroderoididae, only those of Alloglossidium and Macroderoides lack a seminal receptacle, a derived state within the group (Brooks et al., $1985,1989)$. In addition, relative plesiomorphies and apomorphies of characters were checked by reference to the phylogenetic hypothesis for digenean families presented by Brooks et al. $(1985,1989)$, providing a source of secondary outgroup information. Characters for which no state in Alloglossidium was shared with the outgroup taxa were polarized using functional outgroups (Watrous and Wheeler, 1981), permitting character analysis once some of the relationships within the ingroup had been resolved. Complex, multistate transformation series that could not be ordered a priori were analyzed using the unordered states option of the computer program PAUP (Swofford, 1985). The PAUP options mulpars, branch and bound, and global branch swapping were used to ensure identification of the most parsimonious trees. Farris optimization (Farris, 1970) was used to examine the fit of each transformation series.

The following characters and their coded states were used in the phylogenetic analysis.

1. Body shape and proportions: Specimens of Alloglossidium are elongate, filiform, or oval (Schell, 1970) with rounded anterior and posterior ends. Specimens with length-to-width ratios between $3: 1$ and $7: 1$ are considered elongate, those with length-to-width ratios of 9:1 or greater are considered filiform, and those with length-to-width ratio less than 3:1 are considered oval. Macroderoides species have elongate bodies, and this is considered plesiomorphic. The plesiomorphic condition gives rise to the 2 apomorphic states: a filiform body and an oval-shaped body. Unordered analysis of this transformation series is consistent with the hy- pothesis that the 2 apomorphic states are derived independently from the plesiomorphic state.

2. Mean testes-to-ovary diameter: Although absolute gonad size can change during the reproductive life span of a digenean, Dronen and Guidry (1977) found that the ratio of testes diameter to ovarian diameter tended to remain relatively constant. Some members of Alloglossidium have ovarian diameters less than testis diameter, whereas others have ovarian diameters greater than testis diameter. The outgroup species have ovarian diameters less than testis diameter, and this is considered plesiomorphic. The apomorphic state is ovarian diameter greater than testis diameters.

3. Coiling of the uterus: Uteri in gravid specimens of Alloglossidium are either relatively straight, with little intertwining of the ascending or descending arms, or coiled with much intertwining. The plesiomorphic state for digeneans as a whole is a coiled and intertwined uterus (Brooks et al., 1985). However, Macroderoides species have relatively straight uteri with little intertwining or coiling, and this is considered the plesiomorphic condition for Alloglossidium. The coiled and intertwined condition of the uterus, which is considered apomorphic for Alloglossidium, thus appears to represent a secondary return to the plesiomorphic state for all digeneans.

4. Distention of the gravid uterus: In some members of Alloglossidium, the gravid uterus, especially the ascending arm, is greatly distended. In Alloglossidium progeneticum the distention deforms the body. Gravid uteri in other members of Alloglossidium, all members of Macroderoides, and most species of Plagiorchiiformes, are not distended, which is considered plesiomorphic.

5. Anterior testis location: This character is determined by comparing the distance from the anterior margin of the anterior testis to the anterior end of the body with the total body length. Macroderoides species and some members of Alloglossidium have anterior testes located at midbody, and this is considered plesiomorphic. Two apomorphic states can be identified in Alloglossidium: anterior testis located preequatorial and anterior testis postequatorial. Unordered analysis of this transformation series is consistent with the interpretation that the preequatorial testis is derived from a postequatorial testis condition.

6. Size of tegumental spines near the oral sucker: The plesiomorphic state, found in Macroderoides species and some members of Alloglossidium, is tegumental spines 4-7 long by $2-4$ wide at the base. Two apomorphic states can be identified within Alloglossidi$u m$ : large spines that have a minimal length of 12 and width of 4-5, and minute spines. Unordered analysis of this transformation series is consistent with the hypothesis that each apomorphic state is derived independently from the plesiomorphic state.

7. Shape of tegumental spines near the oral sucker: Tegumental spines in some species of Alloglossidium are tapering and recurved, with a notched base. This condition is found in Macroderoides species and is considered plesiomorphic. Other species exhibit recurved spines that are less tapered and lack the basal notch; this condition is apomorphic.

8. Extent of body spination: Tegumental spines in Alloglossidium species, like those of most spined digeneans, decrease in number and size posteriorly. How- 
TABLE I. Character matrix for numerical phylogenetic analysis of 9 Alloglossidium species.

\begin{tabular}{|c|c|c|c|c|c|c|c|c|c|c|c|c|c|c|c|}
\hline \multirow[b]{2}{*}{ Species } & \multicolumn{15}{|c|}{ Characters* } \\
\hline & 1 & 2 & 3 & 4 & 5 & 6 & 7 & 8 & 9 & 10 & 11 & 12 & 13 & 14 & 15 \\
\hline Outgroup $\dagger$ & $0 \neq$ & 0 & 0 & 0 & 0 & 0 & 0 & 0 & 0 & 0 & 0 & 0 & 0 & 0 & 0 \\
\hline A. geminum & 0 & 0 & 0 & 0 & 0 & 0 & 0 & 0 & 1 & 0 & 0 & 0 & 0 & 0 & 1 \\
\hline A. corti & 0 & 0 & 0 & 0 & 0 & 0 & 0 & 0 & 1 & 1 & 0 & 0 & 0 & 0 & 1 \\
\hline A. progeneticum & 0 & 1 & 0 & 1 & 1 & 0 & 0 & 0 & 1 & 1 & 0 & 0 & 1 & 0 & 1 \\
\hline A. renale & 2 & 1 & 0 & 1 & 1 & 0 & 0 & 0 & 1 & 1 & 0 & 0 & 1 & 0 & 1 \\
\hline A. macrobdellensis & 1 & 0 & 0 & 0 & 1 & 1 & 0 & 0 & 0 & 1 & 1 & 1 & 0 & 1 & 1 \\
\hline A. hamrumi & 1 & 0 & 1 & 0 & 2 & 1 & 1 & 1 & 0 & 1 & 1 & 1 & 0 & 1 & 1 \\
\hline A. turnbulli & 1 & 1 & 1 & 0 & 2 & 0 & 1 & 1 & 0 & 0 & 1 & 1 & 0 & 1 & 1 \\
\hline A. hirudicola & 0 & 0 & 1 & 0 & 2 & 2 & 1 & 2 & 2 & 1 & 1 & 1 & 0 & 1 & 1 \\
\hline A. schmidti & 0 & 1 & 1 & 0 & 2 & 2 & 1 & 2 & 0 & 1 & 1 & 1 & 0 & 1 & 1 \\
\hline
\end{tabular}

* 1, Body shape; 2 , ovary size; 3 , uterine coiling; 4 , uterine distention; 5 , anterior testis location; 6 , spine size; 7 , spine morphology; 8 , spination extent; 9 , sucker size; 10, vitellaria extent; 11 , acetabulum location; 12 , cecal extent; 13, cecal bifurcation position; 14, excretory vesicle length; 15, cirrus size.

† Outgroup is actually a composite, based on outgroup comparisons of several taxa, used to facilitate the computer analysis.

$\ddagger 0$, Plesiomorphic condition; 1, 2, apomorphic conditions (see text for arguments of order and polarity).

ever, there is a consistent pattern for posterior extent of spination in individual species. In Macroderoides species and in some Alloglossidium species the spines extend to the posterior end of the worm. This is considered plesiomorphic. In other species of Alloglossidi$u m$, the spines end in the middle of the body whereas the remaining species have the spines only in the region of the oral sucker. Phylogenetic analysis is consistent with an interpretation that the transformation has been one of decreasing posterior extent of spination. A fully spined body is plesiomorphic, a body with spines extending to the middle of the body being derived from the plesiomorphic state, and one with spines restricted to the anterior end derived from that.

9. Relative size of the suckers: Members of Macroderoides have acetabula and oral suckers that are nearly equal in width, and this is considered plesiomorphic. There are 2 apomorphic states: acetabulum smaller than the oral sucker and acetabulum larger than the oral sucker. Unordered analysis of this transformation series is consistent with an interpretation that both apomorphic states are derived independently from the plesiomorphic state.

10. Anterior extent of vitellaria: Among Alloglossidium species, the vitellaria are variable in form, posterior extent, and dorso-lateral confluence. As well, there are reports of variation within a species depending on the host type (Vande Vusse, 1980). However, the anterior extent of the vitellaria in relation to the acetabulum appears to be consistent within species. Macroderoides species never have preacetabular vitellaria, and this condition is considered plesiomorphic for Alloglossidium. Vitellaria extending anterior to the level of the acetabulum is apomorphic.

11. Location of the acetabulum: Macroderoides species have acetabula in the anterior $25-50 \%$ of the body, and this is plesiomorphic for Alloglossidium. Among some species of Alloglossidium, the acetabulum is located in the anterior $10-20 \%$ of the body; this is considered apomorphic.

12. Posterior extent of the ceca: The intestinal ceca of Macroderoides species and most species of Alloglossidium extend to near the posterior end of the body (i.e., the postcecal body length is $12 \%$ or less of the total body length). This condition is common in the digenea and is considered plesiomorphic. Among some species of Alloglossidium, the relative cecal length is much shorter, and the postcecal body length may be $20 \%$ or more of the total body length; this is apomorphic.

13. Position of the cecal bifurcation: Outgroup species have cecal bifurcations approximately $30 \%$ of the total body length (TBL) from the anterior end. This state is not found among species of Alloglossidium, which have bifurcations averaging $20 \%$ TBL or 10 $14 \%$ TBL from the anterior end. Functional outgroup analysis is consistent with an interpretation that having cecal bifurcations averaging 20\% TBL from the anterior end is plesiomorphic for the ingroup. Those species of Alloglossidium having cecal bifurcations averaging $10-14 \%$ TBL from the anterior end are considered apomorphic.

14. Relative length of excretory vesicle: Excretory vesicles are difficult to observe in fixed material, so states for this character were determined from descriptions of living material in the literature. Among members of the ingroup, the vesicle extends anteriorly to the ovary in some species and to the anterior testis in others. In outgroup species, the vesicle extends no further anteriorly than the posterior testis. As with the previous character, there is no shared state between the ingroup and the outgroup. Functional outgroup analysis produced the same results; the excretory vesicle extending anteriorly to the ovary is considered plesiomorphic for the ingroup. The apomorphic state is the vesicle extending anteriorly to the anterior testis.

15. Relative size of cirrus: A requirement in any phylogenetic analysis is establishing the monophyly of the group being analyzed. Macroderoides and Alloglossidium appear to be sister groups, based on the lack of a seminal receptacle. Species of Macroderoides have relatively well developed cirri, a characteristic shared by other members of the family Macroderoididae and most other digeneneans as well. The cirrus is greatly reduced in species of Alloglossidium, which serves as a synapomorphy for the genus. Because all members of the ingroup have a single state distinct from the outgroup, this character does not provide phylogenetic information for resolution of ingroup relationships. This 

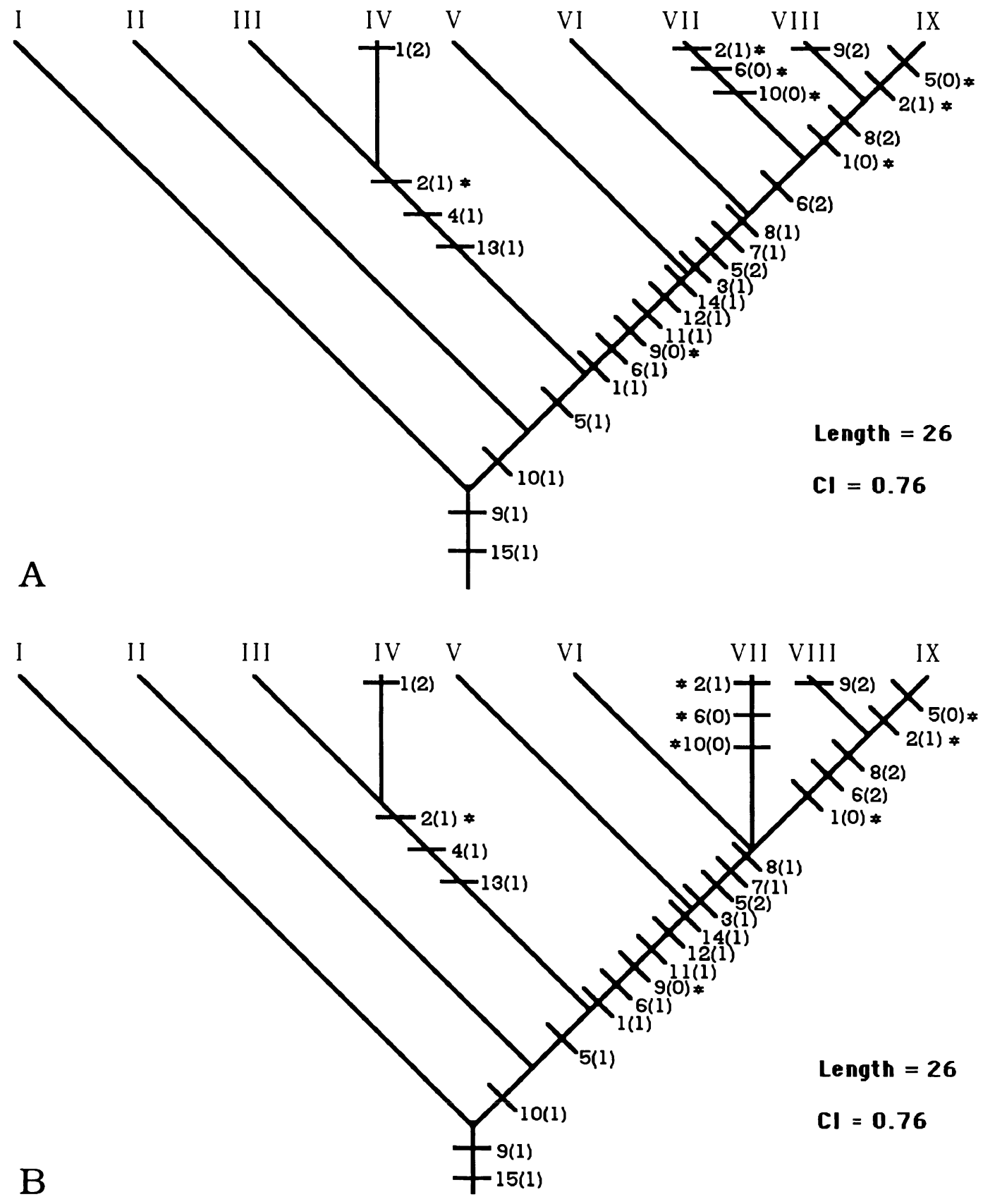

FIGURE 1. Two (A, B) most parsimonious phylogenetic trees generated by phylogenetic analysis of the data matrix shown in Table I for 9 North American species of Alloglossidium. Roman numerals refer to the following species: I, A. geminum; II, A. corti; III, A. progeneticum; IV, A. renale; V, A. macrobdellensis; VI, A. hamrumi; VII, $A$. turnbulli; VIII, $A$. hirudicola; IX, $A$. schmidti. Numbers associated with slash marks indicate the character with the state enclosed in brackets. Refer to text for character identification. An asterisk indicates a putative homoplasy. 

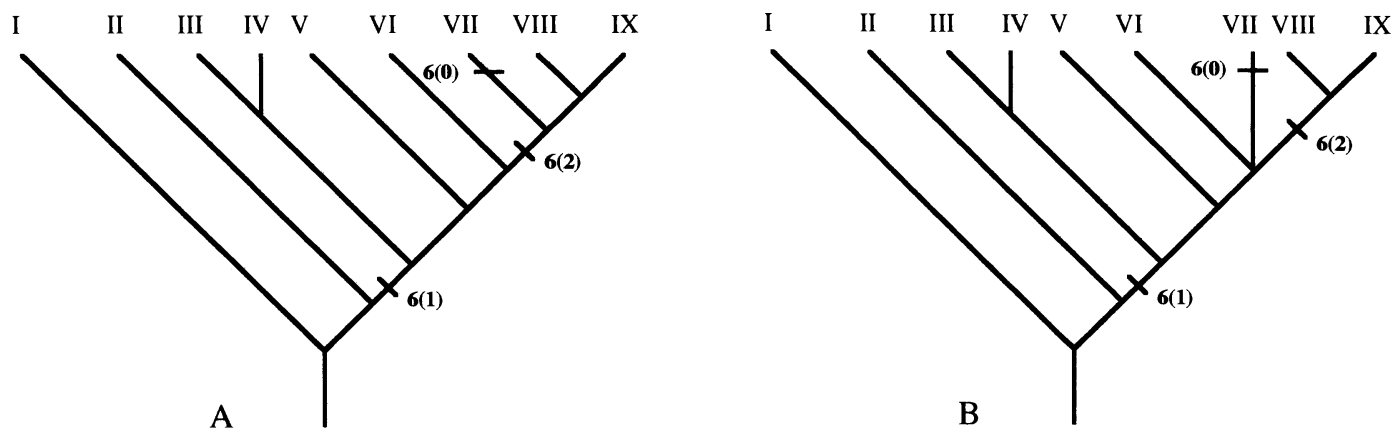

FIGURE 2. Comparison between the 2 phylogenetic trees based on optimization of states for tegumental spine size (character 6). A. Character 6(2) as a synapomorphy for Alloglossidium turnbulli, Alloglossidium hirudicola, and Alloglossidium schmidti. B. Character 6(2) as a synapomorphy for $A$. hirudicola and $A$. schmidti with the relationship between Alloglossidium hamrumi and $A$. turnbulli unresolved. Roman numerals refer to the following species: I, A. geminum; II, A. corti; III, A. progeneticum; IV, A. renale; V, A. macrobdellensis; VI, $A$. hamrumi; VII, A. turnbulli; VIII, A. hirudicola; IX, A. schmidti.

character is included in the analysis because it serves to establish the monophyly of the ingroup.

\section{RESULTS}

\section{Phylogenetic analysis}

Phylogenetic systematic analysis of the data matrix (Table I) produced 2 equally parsimonious phylogenetic trees 26 steps long with a consistency index of $76 \%$ (Fig. 1). The trees disagree in the placement of character state $6(2)$. The hypothesis of phylogeny indicated in Figure $1 \mathrm{~A}$ postulates that $6(2)$ is a synapomorphy for Alloglossidium turnbulli, Alloglossidium schmidti and Alloglossidium hirudicola. The alternate hypothesis postulates that $6(2)$ is a synapomorphy for $A$. hirudicola and $A$. schmidti whereas the relationship between Alloglossidium hamrumi and A. turnbulli remains unresolved (Fig. 1B). The difference between the 2 hypotheses is a result of the optimization of 6(2) and in which ancestor 6(2) first arose (Fig. 2). Because no other character in the current database provides further resolution on this set of species, the relationship between $A$. hamrumi and $A$. turnbulli remains, for now, unresolved. Accordingly, the tree indicated in Figure 1B is the tree that will be used in all subsequent discussions.

This hypothesis of phylogeny (Fig. 1B) indicates that those species found in catfish, Alloglossidium geminum and Alloglossidium corti, are the relatively most basal members of the group, whereas those species having crustaceans as definitive hosts (Alloglossidium renale and $A$. progeneticum) and those having leeches as definitive hosts (Alloglossidium macrobdellensis, A. hirudicola, A. schmidti, A. hamrumi, and A. turnbulli) are monophyletic sister groups derived from the sister group of $A$. corti.

\section{Taxonomic summary}

The following species summaries include phylogenetic diagnoses that refer only to those characters relevant to the phylogenetic analysis. Because not all taxonomic characteristics are relevant in such an analysis, these diagnoses do not substitute for species descriptions. For complete taxonomic descriptions of each species refer to the type description; for the generic diagnosis see Vande Vusse (1980).

\section{Alloglossidium corti (Lamont, 1921) Van Cleave and Mueller, 1932 (Fig. 3)}

Synonyms: Plagiorchis corti Lamont, 1921; Plagiorchis ameiurensis McCoy, 1928; Alloglossidium kenti Simer, 1929.

Definitive hosts: Noturus gyrinus Mitchill, 1817 (type); Noturus miurus Jordan, 1877; Noturus flavus Rafinesque, 1818; Noturus insignis Richardson, 1836; Ictalurus platycephalus Girard, 1859; Ictalurus punctatus Rafinesque, 1818; Ictalurus catus Girard, 1859; Ictalurus melas Rafinesque, 1820; Ictalurus natalis LeSueur, 1819; Ictalurus nebulosus LeSueur, 1819; Anguilla rostrata LeSueur, 1817; Micropterus salmoides Lacépède, 1802; Ambloplites spp.; Chaenobryttus spp.

Distribution: Wisconsin (type), Nebraska, Kansas, Louisiana, Indiana, New York, Mississippi, Missouri, Michigan, Georgia, Kentucky, Texas, California, Arkansas, Minnesota, North Dakota, Idaho, Virginia, Oklahoma, Lake Erie, Ontario.

Specimens examined: USNM no. 60211 (holotype and paratype); HWML nos. 20335, 20336, 20337, 20338, 20339, 20340, 20341, 20342, 20343, 20344, 21464, 21982, 22674, 24972; JPC (10 specimens), WFF (5 specimens), MR (2 specimens).

Diagnosis (based on examination of 65 specimens): 

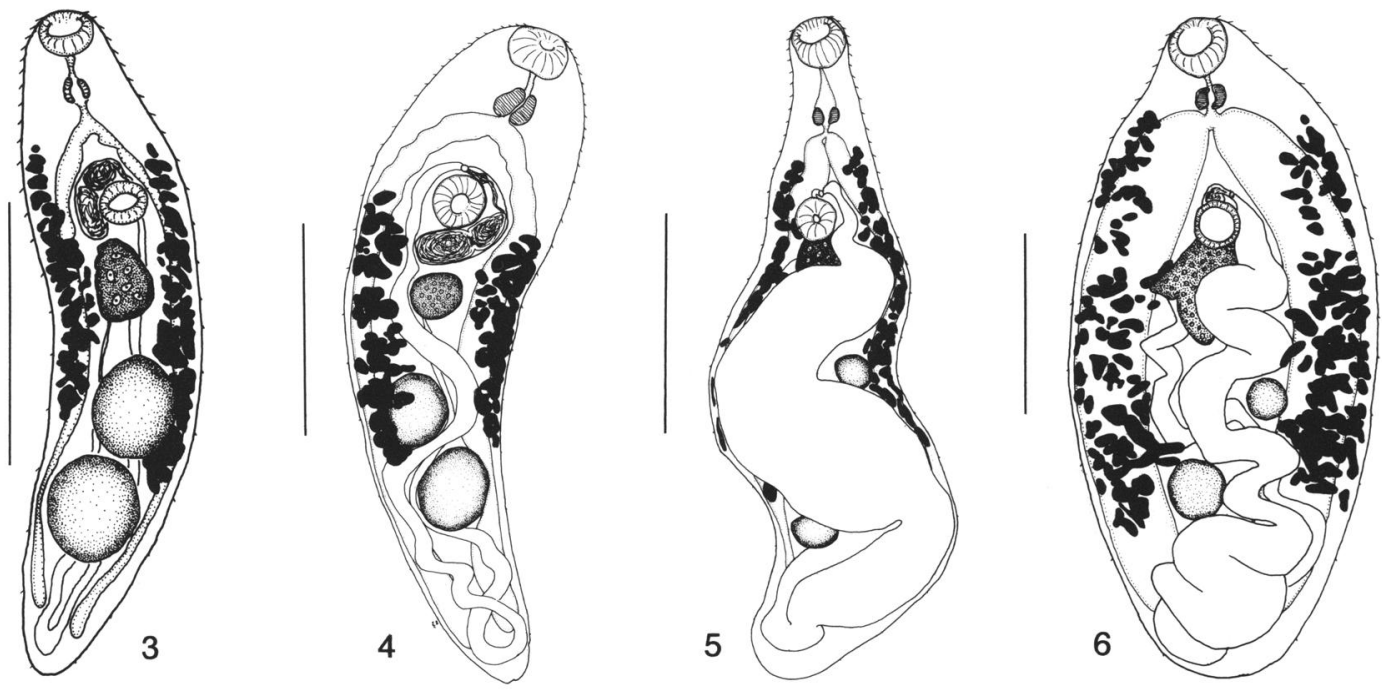

Figures 3-6. Four species of Alloglossidium. 3. Alloglossidium corti, ventral view. 4. Alloglossidium geminum, ventral view. 5. Alloglossidium hirudicola, ventral view. 6. Alloglossidium progeneticum, ventral view. Scale bars equivalent to $0.5 \mathrm{~mm}$.

Body elongate, 833-2,006 (1,199) long, 202-485 (299) wide; ratio of total body length to width 3.4-4.5:1 (4.1: 1). Tegumental spines covering entire body, decreasing in size and number posteriorly. Spines near oral sucker 4-7 long, 2-4 wide at base; recurved, tapering, with notched base. Oral sucker 84-192 (120) in diameter; pharynx 44-128 (64) in diameter. Cecal bifurcation $12-17 \%$ (14\%) TBL from anterior end; ceca extending posttesticularly, terminating $13-16 \%$ TBL from posterior end. Acetabulum 56-140 (85) in diameter, 25$34 \%$ TBL from anterior end. Ratio of oral sucker width to acetabular width 1:0.69-0.73 (1:0.7). Testes oval, tandem to slightly oblique, intercecal; anterior testis $48-53 \%$ TBL from anterior end of body. Cirrus sac 120-240 (190) long, containing bipartite internal seminal vesicle. Genital pore ventral, median, immediately preacetabular. Ovary spherical to oval, smaller than testes. Seminal receptacle absent, Laurer's canal present. Uterus extending posttesticular to posterior of body, relatively straight with little coiling or intertwining of descending or ascending arms, not distended when gravid. Vitellaria in 2 lateral follicular bands, extending from region of pharynx to region of posterior testis. Excretory vesicle extending anteriorly to ovary.

\section{Alloglossidium geminum (Mueller, 1930) Van Cleave and Mueller, 1932} (Fig. 4)

Synonyms: Plagiorchis geminus Mueller, 1930; Glossidium geminum (Mueller, 1930) Yamaguti, 1958.

Definitive hosts: $N$. gyrinus (type), I. melas, I. punctatus, I. nebulosus, I. natalis.

Distribution: Oneida Lake, New York (type), Wisconsin, Ohio, Maine, Massachusetts, Texas, Nebraska, Ontario, Lake Huron, Lake Erie.

Specimens examined: USNM nos. 8564 (holotype), 77898; HWML nos. 20328, 20329, 20330, 20331, 20332, 20333; JPC (10 specimens).

Diagnosis (based on examination of 41 specimens):
Body elongate, 1,715-5,030 (3,720) long, 339-890 (610) wide; ratio of total body length to width 5.05-6.5:1 (6.1:1). Tegumental spines covering entire body, decreasing in size and number posteriorly. Spines near oral sucker 4-7 long, 2-4 wide at the base; tapered, recurved, with a notched base. Oral sucker 136-272 (217) in diameter; pharynx 80-152 (120) in diameter. Cecal bifurcation 11-15\% TBL from anterior end; ceca extending posttesticularly, terminating within $12 \% \mathrm{TBL}$ from posterior end. Acetabulum 108-192 $(\bar{x}=158)$ in diameter, $25-30 \%$ TBL from anterior end. Ratio of oral sucker width to acetabulum width 1:0.71-0.79 (1: $0.75)$. Testes spherical to oval, tandem to slightly oblique, intercecal; anterior testis $48-52 \%$ TBL from anterior end of body. Cirrus sac 370-660 (435) long, containing bipartite internal seminal vesicle. Genital pore ventral, median, immediately preacetabular. Ovary spherical to oval, lobate or smooth, smaller than the testes. Seminal receptacle absent, Laurer's canal present. Uterus extending posttesticular to posterior of body, relatively straight with little coiling or intertwining of the ascending or descending arms, not distended when gravid. Vitellaria in 2 lateral follicular bands, not preacetabular, extending from acetabulum to midlevel of anterior testis or anterior margin of posterior testis. Excretory vesicle extending anteriorly to region of ovary.

\section{Alloglossidium hirudicola Schmidt and Chaloupka, 1969} (Fig. 5)

Definitive hosts: Haemopis lateromaculata Mathers, 1963; Haemopis marmorata Say, 1824; Haemopis plumbea Moore, 1912; Haemopis grandis Verrill, 1874; Macrobdella decora Say, 1824.

Distribution: Wisconsin, Minnesota, Iowa.

Specimens examined: USNM no. 60397 (paratypes), 72299, 73984; MR (22 specimens).

Diagnosis (based on examination of 26 specimens): 
Body elongate, 855-4,295 (2,318) long; 225-1,034 (522) wide; ratio of total body length to width 3.4-5.8:1 (4.5: 1). Tegumental spines only near oral sucker; spines minute, slightly recurved, with no notch at base. Oral sucker 73-257 (161) in diameter; pharynx 48-126 (77) in diameter. Cecal bifurcation approximately $10-15 \%$ TBL from anterior end; ceca extending to or slightly posterior to posterior testis. Acetabulum spherical, 85294 (179) in diameter; 10-20\% TBL from anterior end. Ratio of oral sucker width to acetabular width 1:1.07$1.35(1: 1.15)$. Testes spherical to oval, tandem to slightly oblique, intercecal; anterior testis $40-45 \%$ TBL from anterior end of body. Cirrus sac 80-290 (156) long, containing bipartite internal seminal vesicle. Genital pore ventral, median, immediately preacetabular. Ovary oval to slightly lobate, smaller than testes. Seminal receptacle absent, Laurer's canal present. Uterus extending posttesticular to posterior of body, coiled intertwining of the descending and ascending limbs, not distended when gravid. Vitellaria in 2 lateral follicular bands, extending from region anterior of the acetabulum to posterior testis. Excretory vesicle extending anteriorly to anterior testis.

\section{Alloglossidium progeneticum \\ (Sullivan and Heard, 1969) Font and Corkum, 1975 (Fig. 6)}

Synonym: Macroderoides progeneticus Sullivan and Heard, 1969.

Definitive hosts: Procambarus spiculifer (LeConte, 1856) (type), I. nebulosus.

Distribution: Oconee County, Georgia (type).

Specimens examined: USNM no. 71214 (paratypes); WFF (5 specimens).

Diagnosis (based on examination of 8 specimens): Body elongate, 1,035-1,710 (1,390) long, 243-480 (334) wide; ratio of total body length to width 3.3-5.0:1 (4.2: 1). Tegumental spines covering entire body, decreasing in size and number posteriorly. Spines near oral sucker 4-7 long, 2-4 wide at base; recurved, tapering, with a notched base. Oral sucker 70-120 (91) in diameter; pharynx 30-58 (45) in diameter. Cecal bifurcation 17$22 \%(20 \%)$ TBL from anterior end; ceca extending posttesticularly, ending $7-12 \%(10 \%)$ from posterior end. Acetabulum 66-104 (80) in diameter; $28-38 \%$ (32\%) TBL from anterior end. Ratio of oral sucker width to acetabulum width 1:0.7-0.9 (1:0.8). Testes oblique, intercecal; anterior testis $58-63 \%$ TBL from anterior end of body. Cirrus sac 90-150 long, containing bipartite internal seminal vesicle. Genital pore ventral, median to slightly sinistral, immediately preacetabular. Ovary spherical to oval, smooth to lobate, larger than testes. Seminal receptacle absent, Laurer's canal present. Uterus extending posttesticular to posterior of body, somewhat sinuous with little intertwining of ascending and descending limbs, greatly distended when gravid. Vitellaria in 2 lateral follicular bands, extending from region of cecal bifurcation to region of posterior testis. Excretory vesicle extending anteriorly to level of ovary.

\section{Alloglossidium macrobdellensis Beckerdite and Corkum, 1974}

Definitive hosts: Macrobdella ditetra Moore, 1953 (type), M. decora.
Distribution: Whiskey Bay, Louisiana (type), Wisconsin, Minnesota, Iowa, Ontario (new distribution record).

Specimens examined: USNM no. 72909 (paratype), 73985; HWML no. 20274; JPC (15 specimens); WFF (5 specimens); MR (1 specimen).

Diagnosis (based on examination of 41 specimens): Body filiform, 1,200-5, $150(3,190)$ long, 90-360 (210) wide; ratio of length to width 10.0-39:1 (15:1). Tegumental spines covering entire body, decreasing in size and number posteriorly. Spines near oral sucker greater than 12 in length, 4-5 in width at base. Spines tapering, recurved, with a notched base. Oral sucker 60-120(87) in diameter; pharynx 36-80 (57) in diameter. Cecal bifurcation $9-14 \%$ (12\%) TBL from anterior end; ceca terminating immediately posterior of posterior testis. Acetabulum 60-120 (87) in diameter, approximately $20 \%$ TBL from anterior end. Ratio of oral sucker width to acetabulum width 1:0.96-1.05 (1:1). Testes oval, tandem, intercecal; anterior testis 57-63\% TBL from anterior. Cirrus sac, 120-300 in length, containing internal bipartite seminal vesicle. Genital pore ventral, median, immediately preacetabular. Ovary spherical to oval, smaller than testes. Seminal receptacle absent, Laurer's canal present. Uterus extending posttesticular to posterior of body, relatively straight with little coiling or intertwining of ascending and descending arms, not distended when gravid. Vitellaria in 2 lateral follicular bands; extending from region of cecal bifurcation to anterior testis. Excretory vesicle extending anteriorly to anterior testis.

\section{Alloglossidium renale Font and Corkum, 1975} (Fig. 8)

Definitive hosts: Palaemonetes kadiakensis Rathbun, 1902; Palaemonetes paludosus Gibbes, 1850.

Distribution: Mississippi River, Louisiana (type), North Carolina (new distribution record).

Specimens examined: USNM no. 73881 (paratypes), 78841, 78842, 78843, 78844; HWML no. 20273; WFF (6 specimens).

Diagnosis (based on examination of 22 specimens): Body elongate, 819-2,800 (1,766) long, 333-1,100 (741) wide; ratio of length to width 2.0-2.8:1 (2.4:1). Tegumental spines covering entire body, decreasing in size and number posteriorly. Spines in the region of the oral sucker 4-6 long, 2-3 wide at base; recurved, tapering, with a notched base. Oral sucker 106-220 (150) in diameter; pharynx 38-98 (67) in diameter. Cecal bifurcation approximately $20 \%$ TBL from anterior end; ceca greatly distended, extending posttesticularly almost to end of body. Acetabulum 88-196 (130) in diameter, $22-32 \%(26 \%)$ TBL from anterior end. Ratio of oral sucker width to acetabular width 1:0.7-0.9 (1: 0.8 ). Testes oblique, oval, intercecal; anterior testis 57$64 \%$ TBL from anterior end of body. Cirrus sac 140 230 (180) long, containing bipartite internal seminal vesicle. Genital pore ventral, median, immediately preacetabular. Ovary deeply lobate, larger than testes. Seminal receptacle absent, Laurer's canal present. Uterus extending posttesticular to posterior of body, distended when gravid, somewhat sinuous, ascending and descending arms not intertwined. Vitellaria in 2 lateral follicular bands, extending from region of cecal bifurcation to region of posterior testis. Excretory vesicle extending anteriorly to ovary. 

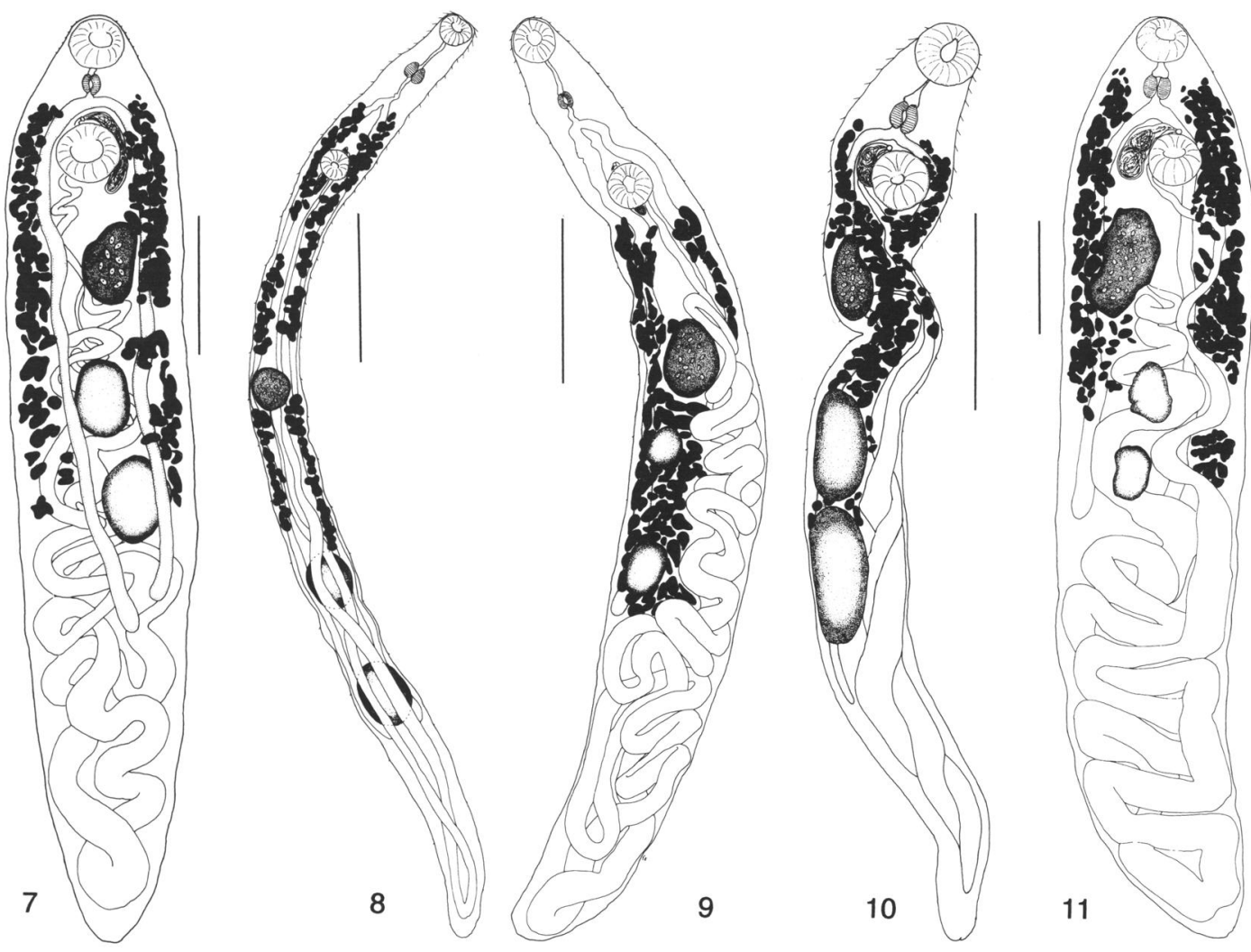

Figures 7-11. Five species of Alloglossidium. 7. Alloglossidium hirudicola, ventral view. 8. Alloglossidium macrobdellensis, ventral view. 9. Alloglossidium turnbulli, ventral view. 10. Alloglossidium hamrumi, ventral view. 11. Alloglossidium schmidti, ventral view. Scale bars equivalent to $0.5 \mathrm{~mm}$.

\section{Alloglossidium turnbulli Neumann and Vande Vusse, 1976 (Fig. 9)}

Definitive hosts: $H$. grandis (type), $H$. plumbea.

Distribution: Lake of the Woods, Minnesota (type), Wisconsin, Michigan, Iowa.

Specimens examined: USNM no. 73515 (paratypes); MR (6 specimens).

Diagnosis (based on examination of 8 specimens): Body filiform, 2,400-5,856 (3,343) long, 220-705 (432) wide; ratio of length to width 7.6-1 1.0:1 (9.3:1). Tegumental spines extending to midbody, decreasing in size and number posteriorly. Spines in the region of the oral sucker 5-7 long, 2-4 wide at base. Spines near oral sucker tapered, recurved, base without notch. Oral sucker 100-218 (150) in diameter; pharynx 39-110 (69) in diameter. Cecal bifurcation 8-15\% TBL from anterior end; ceca extending to or slightly beyond posterior testis. Acetabulum 102-220 (152) in diameter, 15-20\% TBL from anterior end. Ratio of oral sucker width to acetabular width 1:0.97-1.04 (1:1). Testes round to oval, tandem, intercecal; anterior testis 36$45 \%$ TBL from anterior end of body. Cirrus sac 125320 (229) long, containing bipartite internal seminal vesicle. Genital pore ventral, median, immediately preacetabular. Ovary oval, larger than testes. Seminal receptacle absent, Laurer's canal present. Uterus extending posttesticularly to posterior of body, ascending and descending arms coiled and intertwined, not distended when gravid. Vitellaria in 2 lateral follicular bands, extending from anterior of the acetabulum to region of the anterior testis. Excretory vesicle extending anteriorly to level of anterior testis.

\section{Alloglossidium hamrumi Neumann and Vande Vusse, 1976 (Fig. 10)}

Definitive hosts: $H$. plumbea, $M$. decora.

Distribution: Sleepy Eye Lake, Minnesota (type), Wisconsin, Iowa.

Specimens examined: USNM no. 73517 (paratypes); MR (45 specimens).

Diagnosis (based on examination of 47 specimens): Body filiform, 1,913-7,153 (4,353) long, 200-658 (398) wide; ratio of length to width 8.3-12.8:1 (10.7:1). Tegumental spines decreasing in size and number posteriorly ending in region of testes. Spines near oral sucker 12-13 long, 3-5 wide at base, recurved, tapering, basal end not notched. Oral sucker 117-251 (175) in diameter; pharynx 56-119 (87) in diameter. Cecal bifurcation 9-12\% TBL from anterior end of body; ceca extending slightly beyond posterior testis terminating 
25-35\% TBL from posterior end. Acetabulum 115262 (178) in diameter, 13-17\% TBL from anterior end. Ratio of oral sucker width to acetabular width 1:0.951.04 (1:1). Testes oval, tandem, intercecal; anterior testis $38-45 \%$ TBL from anterior end of body. Cirrus sac $150-460$ (333) long, containing bipartite internal seminal vesicle. Genital pore ventral, median, immediately preacetabular. Ovary oval to slightly lobate, smaller than testes. Seminal vesicle absent, Laurer's canal present. Uterus extending posttesticular to posterior of body, ascending and descending limbs coiled and intertwined, not distended when gravid. Vitellaria in 2 lateral follicular bands, extending from pharynx to region of anterior testis. Excretory vesicle extending anteriorly to the anterior testis.

\section{Alloglossidium schmidti Timmers, 1979}

$$
\text { (Fig. 11) }
$$

Synonym: Alloglossidium microspinatum Vande Vusse, 1980.

Definitive host: $H$. grandis (type).

Distribution: Falcon Lake, Manitoba (type), Minnesota, Wisconsin, Iowa.

Specimens examined: USNM no. 73987 (paratypes); MR (10 specimens).

Diagnosis (based on examination of 12 specimens): Body elongate, 1,270-4,020 (2,900) long, 280-840 (640) wide; ratio of length to width 3.9-5.0:1 (4.5:1). Tegumental spines present near oral sucker only, spines minute, slightly recurved, basal end not notched. Oral sucker 105-204 (165) in diameter; pharynx 103-125 (116) in diameter. Cecal bifurcation 8-11\% TBL from anterior end; ceca extending posteriorly to or slightly beyond posterior testis, terminating 30-35\% TBL from posterior end. Acetabulum 100-210 (167) in diameter, $12-16 \%$ TBL from anterior end. Ratio of oral sucker width to acetabular width 1:0.95-1.05 (1:1). Testes oval, tandem to slightly oblique, intercecal; anterior testis $35-43 \%$ TBL from anterior end of body. Cirrus sac 140-260 (209) long, containing bipartite internal seminal vesicle. Genital pore ventral, median to slightly sinistral, immediately anterior to the acetabulum. Ovary spherical to oval, occasionally lobate, larger than testes. Seminal vesicle absent, Laurer's canal present. Uterus posttesticular to posterior of body, coiled, ascending and descending arms intertwined, not distended when gravid. Vitellaria in 2 lateral follicular bands, extending the oral sucker to region of posterior testis. Excretory vesicle extending anteriorly to anterior testis.

\section{DISCUSSION}

Two evolutionary scenarios have been proposed to explain the diversity of life cycle patterns exhibited by Alloglossidium species. The phylogenetic tree (Fig. 1) suggests that those species found in fishes are the most basal species. Furthermore, those species having leeches and those using crustaceans as their respective definitive hosts each form monophyletic lineages, and those two lineages are sister groups. This contradicts the scenario put forth by Riggs and Ulmer (1983) that placed those species parasitizing

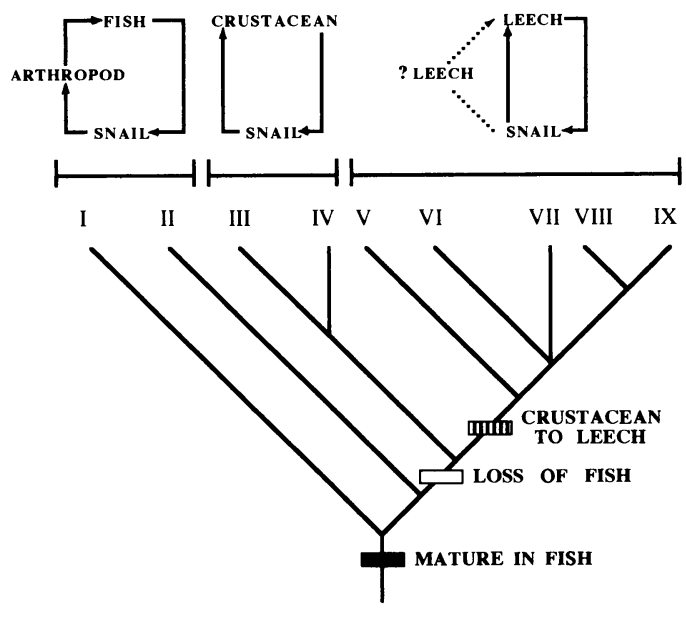

Figure 12. Phylogenetic tree for the 9 North American species of Alloglossidium showing distribution of life cycle characteristics. Loss of a fish definitive host occurred in the common ancestor of the lineage having a crustacean definitive host and the lineage having a leech definitive host. A leech definitive host was acquired by the ancestor of the lineage comprising those species having a leech definitive host. Roman numerals refer to the following species: I, A. geminum; II, $A$. corti; III, $A$. progeneticum; IV, $A$. renale, V, $A$. macrobdellensis; VI, A. hamrumi; VII, A. turnbulli; VIII, A. hirudicola; IX, A. schmidti.

leeches as the basalmost members and those in fishes being the most derived. By contrast, the evolutionary implications of the phylogenetic tree are similar to the hypothesis proposed by Font (1980), in which species using catfish definitive hosts are relatively less derived than those using crustacean and those using leech definitive hosts. Font (1980) proposed that the species using leech definitive hosts and those using crustacean definitive hosts each represented an independent loss of the vertebrate definitive host. As well, Font (1980) postulated that precocial development in an intermediate host was the mechanism by which the vertebrate host was lost for both lineages. This study proposes a somewhat different interpretation, derived from examination of the evolutionary diversification of life cycle patterns in this group within the context of the inferred phylogenetic relationships.

Using the phylogenetic tree generated by this analysis as a template, life cycle characteristics may be mapped to assess whether observed similarities are due to convergence or common ancestry (Brooks et al., 1985; Coddington, 1988; Brooks and McLennan, 1991). Figure 12 shows the phylogenetic tree with life history traits su- 
perimposed. There are 3 general life cycle sequences: snail-arthropod-fish, snail-crustacean, and snail-leech (with perhaps a leech intermediate host for some species [Riggs and Ulmer 1983]). This leads to the conclusion that the 3-host life cycle with a fish definitive host is ancestral to a 2-host life cycle. The lineage utilizing a crustacean as definitive host and the lineage utilizing leeches as definitive host share a common life cycle trait: the lack of a fish definitive host. The most parsimonious explanation has the vertebrate host being lost by the common ancestor of both lineages. If this happened, the ancestral parasite species would have had to develop to the adult stage in what had been the second intermediate host. This host should be shared with one of the descendant parasite lineages. Freshwater crustaceans have been reported as second intermediate hosts for $A$. corti and $A$. geminum. Therefore, it is biologically credible that development to maturity in a freshwater crustacean may have occurred in the ancestor common to the 2 extant lineages of Alloglossidium exhibiting 2-host life cycles. This explains the presence of adult Alloglossidium in freshwater crustacea, but not those in leeches.

Within Alloglossidium, the presence of leeches as definitive host is an apomorphic ecological characteristic shared by 5 species of Alloglossidium that, based on morphological evidence, form a monophyletic group. The most parsimonious explanation is that the ancestor of those 5 Alloglossidium species acquired a leech definitive host. This study proposes that an abridged life cycle arose once in the evolution of this group and that the acquisition of leeches as potential hosts was derived from this ancestral, truncated, 2 -host life cycle. This contrasts with the hypothesis proposed by Font (1980), who postulated that the lineage found in leeches and the one found in crustaceans arose by independent episodes of life cycle truncation. Alloglossidium macrobdellensis, the basalmost member of those species having leech definitive hosts, has a 2-host life cycle, developing to an adult following cercarial penetration of Macrobdella leech species. Riggs and Ulmer (1983) reported that Erpobdella punctata may represent a second intermediate host for $A$. hamrumi. If this is true, it raises the possibility of a return to a 3-host life cycle by more derived species of Alloglossidium. Finally, the first intermediate host for the species of Alloglossidium for which such information has been reported are species of Helisoma. This obser- vation permits the prediction that Helisoma species will serve as first intermediate host for those species for which this information is unknown.

Developmental changes and host switching appear to have been involved in the evolution of the species of Alloglossidium known to have truncated life cycles. The initial ecological truncation producing a mollusc-crustacean life cycle requires some form of developmental change permitting reproductive maturity in what was formerly the second intermediate host. The phylogenetic hypothesis presented herein suggests that the species using leeches as definitive hosts arose through a host switch from an ancestral species using crustaceans as definitive hosts. Fink (1982) noted that the appearance of evolutionary reversals might be one indication of paedomorphic (Alberch et al., 1979) developmental change in the evolutionary diversification of a group. There are several putative evolutionary reversals of characters by the Alloglossidium species inhabiting leeches; perhaps switching to leech hosts resulted in increased levels of paedomorphic development in those species of Alloglossidium. Conversely, earlier development to the adult permitting the initial 2-host life cycle may be the result of peramorphic development (Alberch et al., 1979). However, these speculations regarding heterochronic development can be assessed properly only by examination of each species' ontogeny within the framework of the presented phylogenetic hypothesis.

\section{ACKNOWLEDGMENTS}

We thank J. Ralph Lichtenfels (U.S. National Helminthology Collection, Beltsville, Maryland), William F. Font (Dept. of Biology, Southeastern Louisiana University, Hammond), and M. Riggs (Minnesota Dept. of Natural Resources) for the loan of specimens, and Mary $\mathrm{H}$. Pritchard (Harold W. Manter Laboratory, Division of Parasitology, University of Nebraska State Museum, Lincoln) for access to the parasite collection while in Lincoln. The staff of the Ontario Ministry of Natural Resources, Algonquin Park, permitted and aided in the collection of specimens in the park and this is gratefully acknowledged. Mark E. Siddall contributed valued advice regarding the collection and identification of leeches as well as lively discussion. Financial support during this study was provided by a University of Toronto Open Fellowship to J.P.C. and Natural Sciences and Engineering Research 
Council of Canada operating grant A7696 to D.R.B.

\section{LITERATURE CITED}

Alberch, P., S. J. Gould, G. F. Oster, AND D. B. WAKE. 1979. Size and shape in ontogeny and phylogeny. Paleobiology 5: 296-315.

Brooks, D. R., S. M. BANDONI, C. A. MacDonald, AND R. T. O'GRADY. 1989. Aspects of the phylogeny of the Trematoda Rudolphi, 1808 (Platyhelminthes: Cercomeria). Canadian Journal of Zoology 67: 2609-2624.

, AND D. A. MCLennan. 1991. Phylogeny, ecology and behavior: A research program in comparative biology. University of Chicago Press, Chicago, $434+$ xii p.

, R. T. O'Grady, AND D. R. Glen. 1985. Phylogenetic analysis of the Digenea (Platyhelminthes: Cercomeria) with comments on their adaptive radiation. Canadian Journal of Zoology 63: $411-443$.

Coddington, J. A. 1988. Cladistic tests of adaptional hypotheses. Cladistics 4: 3-22.

Dronen, N. O., AND E. V. GuIDry. 1977. The use of selective ratios as an additional comparative tool in the systematics of some digenetic trematodes (Ochetosomatidae). Proceedings of the Helminthological Society of Washington 44: 223-225.

FARRIS, J. S. 1970. Methods of computing Wagner trees. Systematic Zoology 19: 83-92.

FINK, W. L. 1982. The conceptual relationship between ontogeny and phylogeny. Paleobiology 8: 254-264.
FonT, W. F. 1980. The effect of progenesis on the evolution of Alloglossidium (Trematoda, Plagiorchiida, Macroderoididae). Acta Parasitologica Polonica 27: 173-183.

Maddison, W. P., M. J. Donoghue, AND D. R. MADDISON. 1984. Outgroup analysis and parsimony. Systematic Zoology 33: 83-103.

MORAVEC, F., AND O. AMIN. 1978. Some helminth parasites, excluding Monogenea, from fishes in Afghanistan. Acta Scientiarum Naturalium Academiae Scientiarum Bohemoslovacae-Brno 12: 145.

RiggS, M., AND M. J. Ulmer. 1983. Host-parasite relationships of helminth parasites of the genus Haemopis. I. Associations at the individual host level. Transactions of the American Microscopical Society 102: 213-226.

SCHELl, S. C. 1970. How to know the trematodes. W. C. Brown Company Publishers, Dubuque, Iowa, $355 \mathrm{p}$.

SWOFFORD, D. L. 1985. PAUP (phylogenetic analysis using parsimony). Documentation for version 2.4. Illinois Natural History Survey, Champaign, Illinois, $80 \mathrm{p}$.

VANDE VuSSE, F. J. 1980. Revision of Alloglossidium Simer, 1929 (Trematoda: Macroderoididae) and description of $A$. microspinatum sp. n. from a leech. Journal of Parasitology 66: 667-670.

Watrous, L. E., AND Q. D. Wheeler. 1981. The out-group comparison method of character analysis. Systematic Zoology 30: 1-11. 